bằng DFO.

Vì vấn đề khó tuân thủ, bệnh nhi phải nằm viên để truyền DFO, từ năm 2015 đến nay, các bểnh nhi mắc beta-thalassemia được điêu trị bằng deperiprone (DFP) đường uống. Kết quả nghiên cứu cho thây nồng độ ferritin máu không giảm sau 6 tháng và 12 tháng điều trị, thậm chí còn tăng hơn so với trị ferritin lúc khởi đầu điều trị. Ngoài ra trị số men gan (AST/ALT) cũng không giảm sau 1 năm điều trị. Trong khi các nghiên cứu trước đây đều nhận thấy DFP uống có tác dụng hạ ferritin máu, tuy nhiên tác dụng giảm ứ đọng chất sắt ở gan thì thấp hơn so với DFO $[4,9]$.

Về tác dụng bất lợi của thuốc, DFO chỉ gây phản ứng viêm nhẹ tại chổ tiêm không gây rối loạn tiêu hóa và viêm khớp như ở bệnh nhân được điều trị bằng DFP uống. Cả hai loại thuốc đều không gây giảm bạch cầu hạt trong nghiên cứu này.

Hạn chế của nghiên cứu này là số mẫu nghiển cứu nhỏ, chưa theo dõi mức độ tuân thủ điều trị của bệnh nhân. Ngoài ra, không đo được nồng độ chất sắt tích tụ ở gan và tim trước và sau điều trị.

\section{KẾT LUÂN}

Thải sắt bằng tiêm truyền deferoxamine làm giảm đáng kể ferritin huyết thanh và men gan (AST/ALT). Deferiprone đường uống không có hiệu quả thải sắt và giảm men gan ở trẻ em mắc beta-thalassemia thể nặng. Đề nghị không dùng deferiprone đơn điều trị, nên phối hợp với deferoxamine trong điều trị trẻ em mắc betathalassemia thể nặng.

TÀl LIỆ THAM KHẢO

1. Svasti $M L$, Hieu TM, Munkongdee $T$, et al. (2002) Molecular analysis of beta-thalassemia in South Vietnam. Am J Hematol. 71(2):85-88.

2. Lâm Thị Mỹ (2009) Website BV Nhi Đồng I: http://www.nhidong.org.vn/ Default.aspx

3. Rund D. and Rachmilewitz E. (2000) New trends in the treatment of b-thalassemia. Critical Rewiews in Oncology:Hematology 33:105- 118

4. Olivieri NF, Brittenham GM. (1997) Ironchelating therapy and the treatment of thalassemia. Blood. 1;89(3):739-61.

5. Modell B, Khan M, Darlison M. (2000) Survival in beta-thalassaemia major in the UK: data from the UK Thalassaemia Register. Lancet. 10:355(9220):2051-2.

6. Jamuar SS, Lai AH. (2012) Safety and efficacy of iron chelation therapv with deferiprone in patients with transfusion-dependent thalassemia. Ther Adv Hematol. 3(5):299-307.

7. Botzenhardt S, Felisi M, Bonifazi $D$, et al. (2018) Lona-term safety of deferiprone treatment in children from the Mediterranean reqion with beta-thalassemia maior: the DEEP-3 multi-center observational safety study. Haematologica. 103(1):e1-e4.

8. Mourad FH, Hoffbrand AV, Sheikh-Taha M, et al. (2003) Comparison between desferrioxamine and combined therapy with desferrioxamine and deferiprone in iron overloaded thalassaemia patients. Br J Haematol. 121(1):187-9.

9. Waheed N, Ali S, Butt MA. (2014) Comparison of deferiprone and deferrioxamine for the treatment of transfusional iron overload in children with beta thalassemia major. J Ayub Med Coll Abbottabad. 26(3):297-300.

\title{
ĐÁNH GIÁ SƯ⿱ BIẾN ĐỔI HÌNH THÁI VÀ CHỨC NĂNG TIM Ở BÊ̂NH NHÂN THALASSEMIA TẠI TRUNG TÂM NHI KHOA BÊ̂NH VIÊ̂N TRUNG ƯO'NG THÁI NGUYÊN
}

\author{
Nguyễn Thị Xuân Hương*, Nguyễn Thị Phượng*, \\ Nguyễn Thị Thu Huyền*, Đỗ Thái Sơn*, \\ Bế Hà Thành*, Lê Thị Kim Dung*
}

\section{TÓM TẮT}

Muc tiêu: Đánh giá sự biến đổi hình thái và chức năng tim và mô tả một số yếu tố liên quan tới các biến đổi hình thái và chức năng tim ở bệnh nhân

*Trường Đại học Y Dược Thái Nguyên

Chịu trách nhiệm chính: Nguyễn Thị Xuân Hương

Email: viethuongytn@gmail.com

Ngày nhận bài: 4.01.2021

Ngày phản biên khoa học: 2.3.2021

Ngày duyệt bài: 12.3.2021
Thaslassemia. Phương pháp: Mô tả hàng loạt ca bênh. Đối tượng: 26 bệnh nhân điều trị Thaslassemia tại trung tâm Nhi khoa - Bệnh viện Trung ương Thái Nguyên từ 2/2020 đến 2/2021. Kêt quá: Trên Xquang có $57,7 \%$ có bóng tim to; trên điện tâm đồ có $84,6 \%$ có nhịp tim nhanh; trên siêu âm tim có $53,8 \%$ trẻ có hở van 2 lá, 30,8\% có suy tim, 26,9\% tré có giảm co bóp cơ tim và 19,2\% giãn thất trái. Nồng độ Ferritin huyết thanh tăng cao $\geq 2000 \mathrm{ng} / \mathrm{ml}$ và thời gian mắc bênh trên 5 năm là yếu tố nguy cơ mắc biến chứng tim trên bệnh nhân Thaslassemia. Kêt Iuận: Biến đổi hình thái và chức năng tim trên bệnh nhân 
Thaslassemia chủ yếu là tim to, nhịp tim nhanh, hở van hai lá, suy tim, giảm co bóp cơ tim và giãn thất trái. Có mối liên quan giữa nồng độ Ferritin huyết thanh và thời gian mắc bệnh với biến chứng tim trên bệnh nhân Thaslassemia.

Tư khóa: Thaslassemia, biến đổi hình thái và chức năng tim.

\section{SUMMARY}

\section{EVALUATE THE MORPHOLOGICAL} CHANGES AND HEART FUNCTION IN PATIENTS WITH THALASSEMIA AT THE CENTER OF PEDIATRIC THAI NGUYEN

\section{NATIONAL HOSPITAL}

Objectives: Evaluate the morphological changes and heart function, and describes some of the factors related to the changing morphology and cardiac function in patients Thalassemia. Methods: Describe case series study. Subjects: 26 patients Thalassemia were treated at the center for Pediatric medicine Thai Nguyen National Hospital from 2/2020 to 2/2021. Results: Radiograph, $57.7 \%$ had enlarged heart shadow; Electrocardiogram, $84.6 \%$ had tachycardia; cardiac ultrasound, $53.8 \%$ of children had mitral valve regurgitation, $30.8 \%$ had heart failure, $26,9 \%$ had decreased myocardial contractility and $19.2 \%$ had left ventricular dilatation. Elevated serum ferritin concentrations $\geq 2000 \mathrm{ng} / \mathrm{ml}$ and morbidity over 5 years are risk factors for cardiac complications in patients with Thalassemia. Conclusion: Cardiovascular morphology and heart function changes in patients with Thalassemia are mainly enlarged heart, tachycardia, mitral valve regurgitation, and heart failure, decreased myocardial contractility, and left ventricular dilation. There is a relationship between serum ferritin concentration and duration of disease and cardiac complications in patients with Thalassemia.

Keywords: Thalassemia, changes in heart morphology and function.

\section{I. ĐẶT VẤN ĐỀ}

Thalassemia là bệnh lý huyết học di truyền đặc trưng bởi sự thiếu hụt chuỗi alpha và chuỗi beta trong phân tử hemoglobin của hồng cầu gây ra tình trạng tan máu, thiếu máu và gây ứ sắt thâm nhiễm các cơ quan như tim, gan, tuyến tụy, tuyến giáp và gây rối loạn chức năng ở các cơ quan này [8].

Trên thế giới Thalassemia là một trong các bất thường di truyền phổ biến nhất. Hiện có $7 \%$ người dân trên toàn cầu mang gen bệnh tan máu bẩm sinh; $1,1 \%$ cặp vợ chồng có nguy cơ sinh con bị bệnh hoặc mang gen bệnh. Bệnh phân bố khắp toàn cầu, tỷ lệ cao ở vùng Địa Trung Hải, Trung Đông, châu Á - Thái Bình Dương [8]

ở Việt Nam, Thalassemia phân bố khắp các tỉnh và dân tộc trong cả nước, đặc biệt là các dân tộc ít người ở các tỉnh miền núi. Bệnh viện
Trung ương Thái Nguyên là bệnh viện lớn ở khu vực miền núi phía Bắc, tỷ lệ bệnh nhân đến điều trị bệnh Thalassemia có xu hướng gia tăng [1]. Bệnh thường gây các biến chứng: quá tải sắt, nhiễm trùng, bất thường cấu trúc xương, cường lách, chậm phát triển thể chất, tổn thương tim. Mặc dù tỷ lệ sống và chất lượng cuộc sống của bệnh nhân Thalassemia được gia tăng do truyền máu định kỳ và thải sắt khi có tình trạng quá tải sắt nhưng biến chứng về tim vẫn là nguyên nhân hàng đầu gây tử vong đối với bệnh nhân Thalassemia [5],[8]. Các nghiên cứu về biến đổi về hình thái và chức năng tim ở những bệnh nhân Thalassemia còn ít, chúng tôi chưa ghi nhận nghiên cứu nào về vấn đề này tại Thái Nguyên. Vì vậy chúng tôi tiến hành đề tài này nhằm mục tiêu:

1. Đánh giá sự biến đổi hình thái và chức năng tim ở bệnh nhân Thalassemia điều trị tại trung tâm nhi khoa - Bênh viện TW Thái Nguyền

2. Mô tả một số yếu tố liên quan tới các biến đôi hinh thái và chức năng tim ở các bệnh nhân trên.

\section{II. ĐỐI TƯợNG VÀ PHƯƠNG PHÁP NGHIÊN CỨU 1. Đối tượng nghiên cứu:}

- Tất cả các bệnh nhân đã được chẩn đoán Thaslassemia đang điều trị tại trung tâm Nhi khoa

- Thời gian từ tháng 2 năm 2020 đến hết tháng 2 năm 2021

- Địa điểm: Trung tâm Nhi khoa - Bệnh viện

Trung ương Thái Nguyên

- Tiêu chuẩn loai trừ:

+ Trẻ có tiền sử bị bệnh tim bẩm sinh

+ Trẻ đang mắc các bệnh cấp tính như viêm phổi, nhiễm trùng huyết hay huyết tán miễn dịch thứ phát trong thời gian nằm viện

\section{Phương pháp nghiên cứu}

- Thiết kế nghiên cứu: Mô tả hàng loạt ca bệnh

- Phương pháp chọn mẫu: mẫu thuận tiện

\section{Nội dung nghiên cứu}

- Tiêu chuẩn chẩn đoán Thalassemia dựa vào: lâm sàng, huyết đồ, điện di huyết sắc tố

- Biến đổi tim: khi bệnh nhân có một hoặc nhiều các biểu hiện sau: tim to, suy tim, tăng áp phổi, phì đại thất trái, giảm co bóp cơ tim, giãn buồng tim, rối loạn nhịp tim, hở van tim.

+ Dãn buồng tim: Bệnh nhân có giãn buồng tim trái, tim phải hoặc cả hai

+ Phì đại thất trái: Siêu âm tim khi bề dày cơ thất trái lớn hơn giới hạn trên theo chiều cao

+ Giảm co bóp cở tim: trên siêu âm EF < $55 \%$ hoăc FS $<27 \%$

+ Bóng tim to: chỉ số tim ngực > 55\% (trẻ < 
24 tháng), > 50\% (trẻ $\geq 24$ tháng)

+ Phân độ suy tim: theo tiêu chuẩn của Ross (4 độ)

+ Rối loạn nhịp tim: bất kỳ rối loạn nào ghi nhận trên điện tâm đồ

4. Thu thập số liệu

- Mỗi bênh nhân có một bênh án theo mẫu gồm: tuổi, giới, tuổi chẩn đoán bệnh, tuổi bắt đầu truyền máu, mật độ truyền máu, tuổi bắt đầu thải sắt, triệu chứng lâm sàng do các bác sỹ chuyên khoa Nhi phỏng vấn và khám trẻ.

- Xét nghiệm

+ Siêu âm Doppler tim, Xquang tim phổi, điện di $\mathrm{Hb}$, sinh hóa máu, huyết đồ được thực hiện bởi các bác sỹ tai khoa chẩn đoán hình ảnh, trung tâm huyết học và truyền máu, khoa sinh hóa, khoa thăm dò chức năng Bệnh viện Trung ương Thái Nguyên.

- Xử lý số liệu: bằng phần mềm SPSS 20.

\section{KẾT QUẢ NGHIÊN CỨU}

3.1. Đặc điểm chung của nhóm bệnh nhân nghiên cứu

Trong số 26 bệnh nhân nghiên cứu có 12 nam $(46,2 \%)$ và 14 nữ $(53,8 \%)$, có $96,2 \%$ bệnh nhân có biểu hiện thiếu máu nặng và trung bình.

Bảng 3.1. Đăc điểm chung của nhóm bệnh nhân nghiền cứu

\begin{tabular}{|c|c|}
\hline $\begin{array}{c}\text { Đặc điếm của nhóm } \\
\text { nghiên cứu }\end{array}$ & TB \pm SD $^{(*)}$ \\
\hline Tuối trung bình (tuối) & $9,04 \pm 0,826$ \\
\hline $\begin{array}{c}\text { Tuối chấn đoán bềnh lần đâuu } \\
\text { (tháng) }\end{array}$ & $17,19 \pm 1,472$ \\
\hline Tuối bắt đâu truyên máu (tháng) & $17,19 \pm 1,472$ \\
\hline
\end{tabular}

\begin{tabular}{|l|l|}
\hline Tuối bắt đầu thải sắt (tháng) & $3,46 \pm 0,325$ \\
\hline
\end{tabular}

\begin{tabular}{|c|c|}
\hline $\mathrm{Hb}(\mathrm{g} / \mathrm{l})$ & $64,58 \pm 2,57$ \\
\hline $\mathrm{HC}(\mathrm{T} / \mathrm{l})$ & $2,97 \pm 0,12$ \\
\hline Ferritin huyết thanh $(\mathrm{ng} / \mathrm{ml})$ & $4184 \pm 604,76$ \\
\hline
\end{tabular}

${ }^{(*)}$ TB: trung bình, SD: độ lệch chuấn

Nhận xét: Tuổi trung bình mắc bệnh là 9,04 $\pm 0,826$ tuổi, $\mathrm{Hb}$ trung bình $(\mathrm{g} / \mathrm{l})$ của nhóm bệnh nhân là $64,58 \pm 2,57$; nồng độ Ferritin huyết thanh trung bình $(\mathrm{ng} / \mathrm{ml})$ là $4184 \pm 604,76$

3.2. Biến đổi hình thái và chức năng tim trên nhóm bệnh nhân nghiên cứu

Bảng 3.2. Biên đổi tim trên X quang

\begin{tabular}{|c|c|c|}
\hline Xquang & $\mathbf{n}$ & $\mathbf{\%}$ \\
\hline Bóng tim không to & 11 & 42,3 \\
\hline Bóng tim to & 15 & 57,7 \\
\hline Tống số & $\mathbf{2 6}$ & $\mathbf{1 0 0}$ \\
\hline
\end{tabular}

Nhân xét: Có $57,7 \%$ bóng tim to trên phim chụp Xquang.

Bảng 3.3. Biến đổi tim trên điện tâm đồ

Điên tâm đồ

\begin{tabular}{|c|c|c|}
\hline Tăng gánh thất trái & 8 & 30,8 \\
\hline
\end{tabular}

\begin{tabular}{|c|c|c}
\hline Tần số tim nhanh & 22 & 84,6 \\
\hline
\end{tabular}

Nhận xét: Trên điện tâm đồ có $84,6 \%$ trẻ có nhị tim nhanh, $30,8 \%$ có tăng gánh thất trái.

Bảng 3.4. Biến đổi tim trên siêu âm

\begin{tabular}{|c|c|c|}
\hline Triểu chứng & $\mathbf{n}$ & $\mathbf{\%}$ \\
\hline Hở van 2 lá & 14 & 53,8 \\
\hline Hở van ĐMC & 2 & 7,7 \\
\hline Giãn thất trái & 5 & 19,2 \\
\hline Giảm co bóp cơ tim & 7 & 26,9 \\
\hline Suy tim & 8 & 30,8 \\
\hline
\end{tabular}

Nhận xét: có tới $53,8 \%$ trẻ có hở van 2 lá, $30,8 \%$ có suy tim, $26,9 \%$ trẻ có giảm co bóp cơ tim, và $19,2 \%$ giãn thất trái.

Bảng 3.5. Liên quan giữa nông độ Ferritin huyêt thanh với biến đổi tỉm trên bệnh nhân Thalassemia

\begin{tabular}{|c|c|c|c|c|c|c|}
\hline \multirow{2}{*}{ Berriến đối tim } & \multicolumn{2}{|c|}{ Không } & \multicolumn{2}{|c|}{ Có } & \multirow{2}{*}{ OR (95\%CI) } & \multirow{2}{*}{ p } \\
\cline { 2 - 5 } & $\mathbf{n}$ & $\mathbf{\%}$ & $\mathbf{n}$ & $\mathbf{\%}$ & 8,4 & \multirow{2}{*}{0,038} \\
\hline$<2000 \mathrm{ng} / \mathrm{ml}$ & 7 & 77,8 & 2 & 22,2 & $(1,3-55,4)$ & \\
\hline$\geq 2000 \mathrm{ng} / \mathrm{ml}$ & 5 & 29,4 & 12 & 70,6 & $(1,4)$ \\
\hline
\end{tabular}

Nhận xét: Nhóm bệnh nhân có nồng độ ferritin huyết thanh $\geq 2000 \mathrm{ng} / \mathrm{ml}$ có nguy cơ biến đối tim cao gấp 8,4 lần nhóm bệnh nhân có nồng độ ferritin huyết thanh $<2000 \mathrm{ng} / \mathrm{ml}$.

Bảng 3.6. Liên quan giữa thời gian mắc bệnh với biến đổi tim trên bệnh nhân Thalassemia

\begin{tabular}{|c|c|c|c|c|c|c|}
\hline \multirow{2}{*}{$\begin{array}{l}\text { Biến đối tim } \\
\text { Thời gian mắc bệnh }\end{array}$} & \multicolumn{2}{|c|}{ Không } & \multicolumn{2}{|c|}{ Có } & \multirow{2}{*}{ OR $(95 \% C I)$} & \multirow{2}{*}{$\mathbf{p}$} \\
\hline & $\mathbf{n}$ & $\%$ & $\mathbf{n}$ & $\%$ & & \\
\hline $\begin{array}{l}<5 \text { nằm } \\
>5 \text { năm }\end{array}$ & $\frac{6}{6}$ & $\frac{85,7}{316}$ & $\frac{1}{13}$ & $\frac{14,3}{684}$ & 13 & 0,026 \\
\hline
\end{tabular}

Nhận xét: Nhóm bệnh nhân có thời gian mắc bệnh trên 5 năm có nguy cơ biến đối tim cao gấp 13 lần so với nhóm bệnh nhân có thời gian mắc bệnh dưới 5 năm.

\section{BÀN LUÂ̂N}

Qua nghiên cứu 26 bệnh nhân Thalassemia có $46,2 \%$ bệnh nhân nam và $53,8 \%$ bệnh nhân nữ, có $96,2 \%$ bệnh nhân có biểu hiện thiếu máu nặng và trung bình. Thời gian điều trị trung bình $9,04 \pm 0,826$ tuổi.

Biến đổi hình thái và chức năng tim ở bệnh nhân Thalassemia. Biến chứng tim 
mạch là nguyên nhân chính gây tử vong ở bênh nhân thalassemia. Có nhiều nguyên nhân dẫn đến tổn thương tim như thiếu oxy tổ chức mạn tính, tăng tần suất tống máu của tim, tình trạng tăng đông, tổn thương mạch máu tim và quá tải sắt tại tim .. Các biến chứng của tim rất đa dạng như phì đại cơ tim, tăng áp lực động mạch phổi, rối loạn nhịp tim, giảm sức bóp cơ tim và cuối cùng là suy tim $[2],[3],[5]$.

Biến đổi tim trên Xquang: Kết quả nghiên cứu của chúng tôi có $57,7 \%$ bóng tim to trên phim chụp Xquang tim phổi. Kết quả này cũng tương tự nghiên cứu của Nguyễn Việt Hà là $62,2 \%$ [2 ], thấp hơn của Mã Phương Hạnh là 87,5\% [3].

Biến đổi tim trên điện tâm đồ: Kết quả nghiên cứu của chúng tôi trên điện tâm đồ chủ yếu gặp nhip tim nhanh chiếm $84,6 \%$. Nghiên cứu của chúng tôi cao hơn tác giả Nguyễn Việt Hà là 75,6\%[2], Mã Phương Hạnh là 56,25\%[3]. Nghiên cứu của Noori trên 80 bệnh nhân Thalassemia cho thấy có tần số tim cao hơn nhóm chứng $(p<0,05)[6]$. Chúng tôi cũng ghi nhận có $30,8 \%$ tăng gánh thất trái trên điện tâm đồ.

Biến đổi tim trên siêu âm: Nghiên cứu của chúng tôi ghi nhận có 16 (61.5\%) bệnh nhân tổn thương van tim, chủ yếu là van 2 lá, 19,2\% giãn thất trái. Giảm co bóp cơ tim với chỉ số $\mathrm{EF}<55 \%$ là $26,9 \%$, tỷ lệ này trong nghiên cứu của Nguyễn Việt Hà là 21,6\%[2]. Nghiên cứu của Norri cho thấy chỉ số EF của nhóm bệnh thấp hơn nhóm chứng [6]. Giảm co bóp cơ tim là một yếu tố tiên lượng nặng đối với bệnh Thalassemia [5].

Mối liên quan giữa nồng độ Ferritin huyết thanh với biến đổi tím của bệnh nhân Thalassemia. Kết quả nghiên cứu cho thấy nhóm bệnh nhân có Ferritin huyết thanh $\geq$ $2000 \mathrm{ng} / \mathrm{ml}$ có nguy cơ biến đổi tim cao gấp 8,4 lần nhóm có Ferritin huyết thanh dưới $2000 \mathrm{ng} / \mathrm{ml}(p<0,05)$. Tình trạng quá tải sắt kéo dài tại tim là một trong nguyên nhân phổ biến làm cơ tim bị tổn thương dẫn đến suy tim, rối loạn nhịp tim [5]. Kết quả này cũng tương tự với kết quả nghiên cứu của Nguyễn Việt Hà (2018), nhóm bệnh nhân có Ferritin huyết thanh cao trên $2000 \mathrm{ng} / \mathrm{ml}$ có nguy cơ biến chứng tim gấp 5,7 lần so với nhóm có Ferritin huyết thanh dưới $2000 \mathrm{ng} / \mathrm{ml}$ [2]. Tác giả Sultan Aydın Köker (2019) cho thây có mối liên quan giữa chỉ số EF giảm trên siêu âm với chỉ số Ferritin huyết thanh tăng cao [7]. Theo Borgana-pignatti (2004) nghiên cứu trên 50 bệnh nhân Thalassemia tử vong có $60 \%$ bệnh nhân có Ferritin trên $2500 \mathrm{ng} / \mathrm{ml}$ và ngưỡng Ferritin cao có tiên lượng không tốt cho bệnh nhân [4]. Theo báo cáo của
Liên đoàn thalassemia quốc tế năm 2008 là $70 \%$ bệnh nhân có ferritin > $2500 \mathrm{ng} / \mathrm{ml}$ trong thời gian dài trên một năm sẽ có nguy cơ bị biến chứng tim mạch, trong khi bệnh nhân có ferritin $<1000 \mathrm{ng} / \mathrm{ml}$ sẽ không có nguy cơ này [5].

Mối liên quan giữa thời gian mắc bệnh với biến đổi tim của bệnh nhân Thalassemia. Nghiên cứu của chúng tôi thấy nhóm bệnh nhân có thời gian mắc bệnh trên 5 năm có nguy cơ biến đổi tim gấp 13 lần so với nhóm có thời gian mắc bệnh dưới 5 năm $(p<0,05)$. Kết quả này cũng tương tư Sultan Aydın Köker (2019) cho thấy tuổi bị bệnh càng cao thì chức năng tim càng giảm [7].

\section{KẾT LUÂ̂N}

- Biến đổi hình thái và chức năng tim trên bệnh nhân Thalassemia chủ yếu là tim to, nhịp tim nhanh, hở van hai lá, suy tim, giảm co bóp cơ tim và giãn thất trái.

- Nồng độ Ferritin huyết thanh tăng cao $\geq$ $2000 \mathrm{ng} / \mathrm{ml}$ và thời gian mắc bệnh trên 5 năm là yếu tố liên quan đến biến đổi tim trên bệnh nhân Thalassemia.

\section{TÀI LIẸU THAM KHẢO}

1. Nguyễn Thị Hà, Hoàng Thị Huế (2017), "Nghiên cứu đăc điểm dich tễ hoc lâm sàng và diền biến bệnh Thalassemia tại Thái Nguyên", Tạp chí Y học thành phố Hồ Chí Minh, phụ bản tập 211, số 4, trang 321-324.

2. Nguyển Việt Hà, Nguyễn Ngọc Sáng, Vũ Văn Quang (2018), "Biên đổi tim mach ở bênh nhân Betha Thalassemia tại bệnh viện trẻ em Hải Phòng", Tap chí Y học Việt Nam, tập 466, tháng 5 số đặc biệt, tr 481-485.

3. Mã Phướng Hạnh (2009), " Đặc điểm bênh nhân Thalassemia thể năng có ứ sắt tai bênh viên Nhi đồng I", Tap chí Y học thành phố Hồ Ċhí Minh, phụ bản tâp 13 số 1 , chuyên đề Nhi khoa, tr 167-173.

4. Borgana-Pignatti $C$, Rugoloto $S$, De Stefano P, et al (2004), "Survival and complications in patients with thalassemia major treated with transfusion and defeoxamine", Haematologica, Page 1187-1193.

5. Cappellini MD., Cohen A., Androulala E. et al (2008). Guidelines for the clinical management of thalassemia. Thalassaemia International Federation, 2nd edition.

6.Nouri N, Naderi M, Rajaie S et al (2013) "Evaluation of cardiac function in patients with thalassemia intermedia. Iran J Ped Hematol Oncol". 3(1): Page 193-199.

7. Sultan Aydın Köker, Gönül Oktay, Derya Duman et al (2019). "Assessment of cardiac functions in thalassemia patients with m-mode echocardiography ". Cumhuriyet Medical Journal, Volume: 41, Number: 4, Page 739-742

8. Thalassemia Internation Federation annual report 2013. 